\title{
Integrated Prediction Error Filter Analysis Application On Lake Towuti
}

\author{
Aplikasi Metode Integrated Prediction Error Filter Analysis Pada Danau Towuti
}

\author{
Taufik, M. H. ${ }^{1 *}$, Winardhi, I. S. ${ }^{2}$, dan Bijaksana, S. ${ }^{3}$ \\ ${ }^{1}$ Program Studi Teknik Geofisika, Fakultas Teknik Pertambangan dan Perminyakan, Institut Teknologi Bandung, \\ Jalan Ganesa 10 Bandung, 40132 \\ ${ }^{2}$ Kelompok Keahlian Seismologi Eksplorasi dan Rekayasa, Fakultas Teknik Pertambangan dan Perminyakan, \\ Institut Teknologi Bandung, Jalan Ganesa 10 Bandung, 40132 \\ ${ }^{3}$ Kelompok Keahlian Geofisika Global, Fakultas Teknik Pertambangan dan Perminyakan, Institut Teknologi Bandung, \\ Jalan Ganesa 10 Bandung, 40132 \\ *Email:
}

Submit: 10 Juni 2019; Revised: 22 Juli 2019; Accepted: 26 Agustus 2019

\begin{abstract}
Every naturally-occurred phenomenon on earth is related to cyclicity. On a larger scale, it can be defined as the occurance of climate periodicity which is caused by the revolution of earth towards the sun. It can also be examined on a smaller process such as the days and nights cycles, as the effect of earths rotation. This research will specifically discuss about the cyclicity of grain size changes in sediments from lake Towuti, Indonesia. The cyclicity of the sediments is deduced using Integrated Prediction Error Filter Analysis (INPEFA) trends. The INPEFA trends are used to analyse the probability of sediments distribution by simply calculating the cumulative errors between predicted and actual data. Unlike any other implementation of INPEFA that mainly observing lithology controlled by sea level changes, this research is aimed at applying INPEFA to enhance well correlation process across an area that is strongly influenced by rainfall intensity and some climatically-driven processes. By correlating the sediment units, the lateral distribution of the climatically-driven diatom ooze will eventually help a better understanding of paleoclimate events on lake Towuti. This research is aimed at constructing and applying systematic algorithm on INPEFA logs calcultation. Two main cores that construct the INPEFA calculation are trend removal process and autoregressive coefficients calculation using Burgs method. When dealing with real datasets the trend removal process is an imperative process to prevent ambiguous INPEFA trend. Moreover, the use of trend removal process is also favourable in interpreting INPEFA trends for various cyclicity periods, this is achieved by varying the input parameters on the trend removal process. Autoregressive coefficients calculation on the other hand is the keystone that constructs the INPEFA logs calculation process. Well correlations process is successfully achieved through interpreting the INPEFA trends logs. Validation of the INPEFA logs shows good correlation between the result and core sample from lake Towuti with widely-distributed tephra being the
\end{abstract}

main key validator. The changes in INPEFA trends is interpreted to be linked with the change in grain size and also in sediments impedance. Comparing and validating the INPEFA trends with two seismic traces from the lake reveals that the turning point of INPEFA trends are associated with strong reflection on the seismic traces. We approach the building of pseudo-INPEFA section through applying optimum Wiener filter (OWF) during the multi-attribures analysis. The lateral continuation of predicted pseudo-log was improved, overall correlation showed an increase by $15 \%$ and a decreased in error value by $25 \%$.

Keywords: Autoregressive Burgs Coefficient, Lake Towuti, INPEFA, OWF, trend removal, Well Correlation

\begin{abstract}
Abstrak: Seluruh proses yang terjadi pada alam dapat dipandang sebagai peristiwa yang berulang (siklus). Siklusitas ini dapat dipandang pada skala kecil seperti siklus begantinya malam dan siang akibat aktivitas rotasi bumi pada sumbunya, atau dapat juga dipandang pada skala yang lebih besar seperti pergantian musim dan iklim sebagai akibat dari aktivitas revolusi bumi terhadap matahari. Penelitian ini mencoba mendeduksi proses siklusitas dari perubahan ukuran besar butir (kasar dan halus) suatu batuan. Penelitian difokuskan untuk melakukan analisa sebaran litologi pada Danau Towuti menggunakan Integrated Prediction Error Filter Analysis (INPEFA). Secara umum, metode INPEFA digunakan pada proses korelasi sumur saat data gamma ray (GR) log yang digunakan sulit untuk diinterpretasi. Secara spesifik, metode INPEFA diharapkan mampu meningkatkan proses korelasi sumur dalam memetakan unitunit sedimen pada Danau Towuti. Berbeda dengan analisa INPEFA yang umumnya dilakukan pada lingkungan yang didominasi oleh perubahan muka air laut, eksperimen yang dilakukan akan difokuskan untuk dapat mengaplikasikan metode ini pada data yang didominasi oleh perubahan curah hujan dan perubahan iklim. Analisa sebaran INPEFA
\end{abstract}


diharapkan mampu meningkatkan analisa persebaran satuan batuan diatom ooze yang terbentuk akibat proses iklim purba pada Danau Towuti. Metode INPEFA secara umum tersusun oleh dua proses utama, perhitungan koefisien Burg dan proses trend removal. Sebagi proses utama, variasi nilai parameter pada perhitungan koefisien Burg tidak akan memengaruhi interpretasi INPEFA yang dilakukan. Proses trend removal penting untuk mengatasi kendala data lapangan yang terganggu eror saat proses akuisisi dilakukan sehingga data bersifat tidak stasioner. Variasi parameter pada tahapan ini juga membantu analisa yang dapat bersifat short-term dan long-term cyclicity. Hasil INPEFA yang dilakukan mampu tervalidasi dengan data litologi, khususnya dengan litologi tephra yang tersebar secara luas, dan data tras seismik yang tersedia pada lapangan penelitian. Metode INPEFA dapat membantu proses korelasi sumur pada Danau Towuti saat data GR log yang digunakan berbeda pada sumur yang tersedia. Peningkatan hasil multiatribut dapat didekati dengan mengaplikasikan filter Wiener optimum (FWO) sebagai tambahan atribut. Hasil penampang yang didapatkan setelah FWO mampu menunjukkan kontinuasi yang lebih baik serta nilai korelasi dan eror yang masing-masing meningkat $15 \%$ dan berkurang $25 \%$.

Kata kunci: Koefisien Autoregresi Burg, Danau Towuti, FWO, pseudo-INPEFA, trend removal

\section{PENDAHULUAN}

Seluruh proses yang terjadi pada alam dapat dipandang sebagai peristiwa yang berulang (siklus). Siklusitas ini dapat dipandang pada skala kecil seperti siklus begantinya malam dan siang akibat aktivitas presisi bumi pada sumbunya, atau dapat juga dipandang pada skala yang lebih besar seperti pergantian musim dan iklim sebagai akibat dari aktivitas rotasi bumi terhadap matahari. Penelitian ini akan mencoba menggunakan metode Integrated Prediction Error Filter Analysis (INPEFA) dalam mengidentifikasi siklusitas tersebut. Secara umum, metode INPEFA merupakan metode yang pada umumnya digunakan untuk melakukan korelasi sumur, saat data gamma ray (GR) log yang biasa digunakan, memiliki hasil bacaan berbeda pada saat membaca litologi yang sama. Siklus perubahan ukuran butir ini dapat didekati dengan hasil trend INPEFA yang digunakan, nilai GR log yang rendah (kasar) akan berasosiasi dengan trend INPEFA negatif dan berlaku sebaliknya pada bacaan GR log tinggi (halus) (Nio dkk. 2005; Prabowo dkk. 2011; Soua 2012). Penelitian ini menggunakan asumsi yang sama dalam mencoba mendeduksi proses siklusitas dari perubahan ukuran besar butir (kasar dan halus) suatu batuan pada kawasan Danau Towuti.

Penelitian ini akan berfokus pada pemahaman metode INPEFA dan pengaplikasiannya pada data sintetik dan data lapangan dari Danau Towuti sebagai metode tambahan dalam melakukan korelasi sumur berdasarkan litologi penyusunnya. Dalam membantu proses korelasi, metode INPEFA digunakan sebagai alat untuk mendeduksi siklus dari perubahan kasar dan halusnya litologi pada Danau Towuti menggunakan data GR log yang berbeda antar kedua sumur. Secara lebih spesifik, Gambar 1 menunjukkan fokus dari daerah penelitian. Terdapat beberapa situs pengambilan data sedimen dan borehole logging yang ditunjukkan masing-

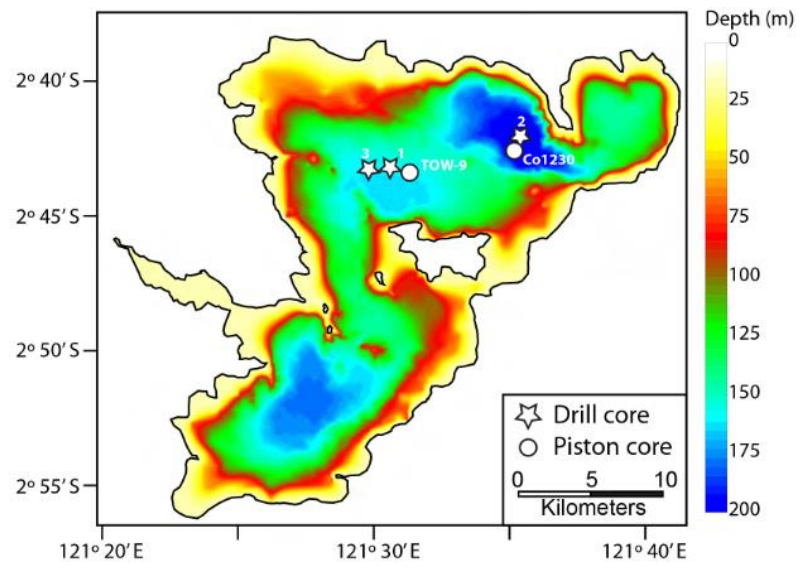

Gambar 1. Lokasi Danau Towuti dan beberapa titik situs pengambilan data (Russel dkk. 2016).

masing dengan tanda bintang dan tanda lingkaran berwarna putih.

Setelah tervalidasi secara vertikal pada kedua sumur, interpretasi sebaran perubahan butir secara lateral akan didekati dengan peyusunan penampang pseudo-INPEFA dan aplikasi metode filter Wiener optimum (FWO). Berbeda dengan analisa INPEFA yang umumnya dilakukan pada lingkungan yang didominasi oleh perubahan muka air laut, eksperimen yang dilakukan akan difokuskan untuk dapat mengaplikasikan metode ini pada data yang didominasi oleh perubahan curah hujan dan perubahan iklim. Terdapat lapisan yang sangat dikontrol oleh perubahan iklim (lapisan diatom) dan lapisan tefra, akibat letusan gunung api, yang tersebar secara merata pada kedua sumur. Sehingga kedua satuan batuan tersebut dapat dijadikan validator dan marker. Analisa sebaran litologi yang dihasilkan diharapkan mampu meningkatkan analisa perubahan iklim purba pada Danau Towuti.

\section{METODOLOGI}

\subsection{Autoregresi Linier}

Autoregresi linier atau secara umum dikenal sebagai linear prediction, adalah sautu proses matematis yang bertujuan untuk memprediksi nilai suatu data deret waktu dengan dirinya sendiri berdasarkan besar lag yang digunakan. Secara matematis, suatu fungsi $a(n)$ atau operasi matematis dapat dikatakan bersifat autoregresi linier, adalah apabila proses tersebut dapat dijabarkan melalui recursive difference equation (Huang 2014).

\section{$2.2 \quad$ Filter Burg}

Filter Burg merupakan pengaplikasian dari teori linear prediction filter. Proses filter Burg mengimplementasikan dan mengikutsertakan backward dan forward prediction error sehingga hasil erornya minimum (Teja dkk. 2017). Secara matematis, perhitungan koefisien autoregresi Burg didasari pada peminimalan nilai eror forward prediction dan backward prediction yang dilakukan. Meminimalkan kedua eror 

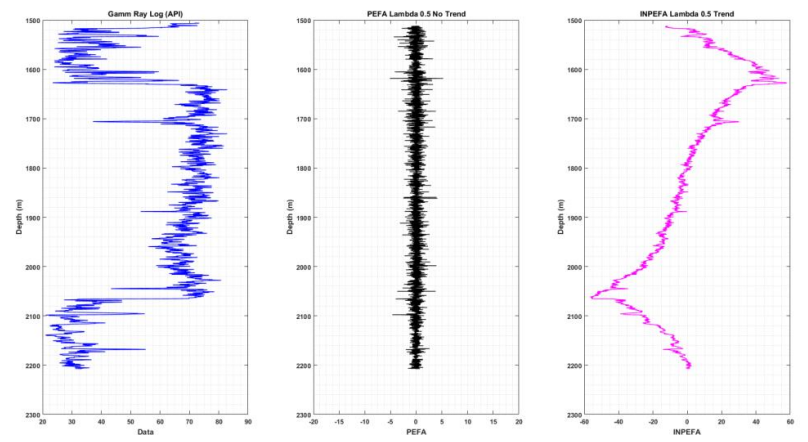

Gambar 2. Hasil Eksperimen Efek Parameter Algoritma Burg. Dari kiri ke kanan merupakan data masukan gamma ray Log, hasil prediction error filter analysis (PEFA), dan hasil Integrated Prediction Error Filter Analysis (INPEFA) dengan parameter masukan Burg 'orde' bernilai 2.

tersebut akan bisa dicari koefisien baru yang mampu menjadi filter dalam langsung memprediksi perhitungan eror yang dilakukan (Vaidyanathan 2008).

\section{$2.3 \quad$ Trend Filtering}

Salah satu dari dua proses utama pada proses perhitungan INPEFA adalah proses trend removal. Hal ini dilakukan untuk mengatasi masalah dalam proses akuisisi data di lapangan. Pada penelitian ini, algoritma yang digunakan pada proses trend removal adalah 'L1TF' atau 11 norm trend filtering. Secara umum, proses ini dilakukan pada suatu data deret waktu sedemikian rupa sehingga data tersebut menjadi stasioner. Karena sejatinya sifat stasionaritas suatu kumpulan data hanya ditentukan oleh partisi yang dilakukan pada data, diperlukan analisa lanjut mengenai efek perubahan window pada penelitian ini. Parameter masukan yang digunakan pada aplikasi dari algoritma tersebut salah satunya ditentukan oleh panjang window yang direpresentasikan dengan parameter 'lambda' pada algoritma tersebut.

\subsection{Filter Wiener Optimum}

Pada penelitian ini, aplikasi lain dari filter Wiener optimum (FWO), yang pada umumnya diterapakan pada proses dekonvolusi tahapan pengolahan data seismik, adalah dengan menambahkan atribut hasil FWO pada tahapan multiatribut seismik. Filter Wiener mampu memprediksi suatu data deret waktu tanpa dilimitasi oleh jumlah panjang data masukan.

\section{HASIL DAN PEMBAHASAN}

\subsection{Analisa Algoritma Burg}

Hasil analisis pada eksperimen pertama, pada Gambar 2 dan Gambar 3, digunakan data masukan yang sama. Data yang digunakan merupakan data sintetik yang disusun untuk merepresentasikan lapisan berbutir halus (GR log tinggi) diantara lapisan berbutir kasar (GR log rendah). Hasil yang didapatkan dengan memvariasikan nilai 'orde' pada algortima Burg adalah pada trend INPEFA yang dihasilkan. Pada data yang memiliki panjang data 4000, saat digunakan nilai
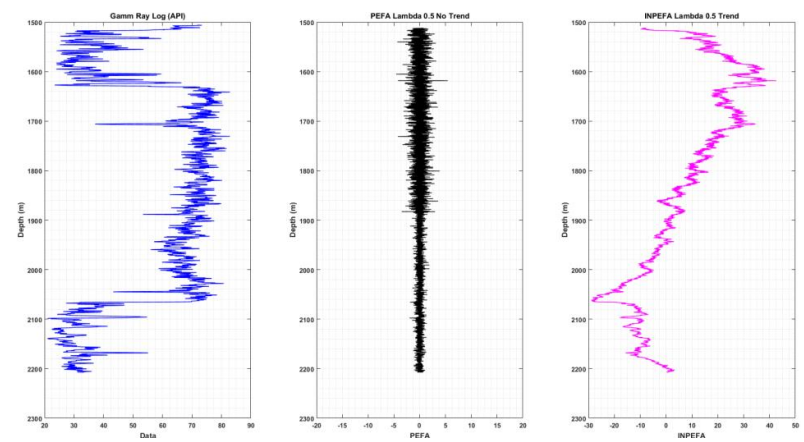

Gambar 3. Hasil Eksperimen Efek Parameter Algoritma Burg. Dari kiri ke kanan merupakan data masukan gamma ray Log, hasil prediction error filter analysis (PEFA), dan hasil Integrated Prediction Error Filter Analysis (INPEFA) dengan parameter masukan Burg 'orde' bernilai 2000.

'orde' bernilai 2000, hasil perhitungan PEFA pada gambar 3 , menunjukkan nilai eror yang terbagi menjadi dua bagian utama. Nilai 'orde' pada algoritma Burg merepresentasikan jumlah data, forward dan backward, yang digunakan untuk mempediksi suatu data deret waktu. Meskipun menghasilkan nilai PEFA yang relatif berbeda, nilai INPEFA yang dihasilkan pada Gambar 2 dan Gambar 3 tidak memiliki perbedaan yang signifikan dalam kuantitas pola trend INPEFA yang dihasilkan. Sehingga didapatkan bahwa nilai INPEFA tidak dipengaruhi oleh besar 'orde' yang digunakan.

\subsection{Analisa Algoritma Trend Filtering}

Eksperimen yang tertera pada gambar 4 dilakukan dengan memilih data masukan yang didominasi oleh GR log rendah, sedangkan pada gambar 5 digunakan data dengan dua dominasi nilai dominan GR log. Jika dibandingkan hasil kedua INPEFA yang didapatkan, proses trend filtering mampu menghasilkan pola trend INPEFA yang lebih representatif. Pola trend INPEFA akan bernilai negatif (mengiri) saat membaca bacaan GR log rendah begitu pula sebaliknya. Hal ini diakibatkan oleh hasil prediksi filter Burg yang relatif lebih rendah dari data yang seharusnya saat memprediksi bacaan data masukan yang rendah, sehingga akan menghasilkan selisih antara data dengan hasil prediksi yang bernilai negatif. Data yang tidak stasioner akan menyebabkan pola trend INPEFA yang tidak representatif dalam menggambarkan besar/kecil nya data masukan yang digunakan. Pada Gambar 4 dan 5 kolom keempat, trend INPEFA justru menghasilkan trend yang positif (kurva biru) saat membaca interval dengan nilai GR log rendah. Dengan menggunakan algoritma trend filtering tersebut, analisis lanjut berkaitan dengan panjang-pendek nya siklusitas yang hendak diteliti juga dapat dilakukan. Hal ini dilakukan dengan mengubah-ubah nilai window pada algoritma tersebut.

Gambar 6 dan 7 menunjukkan bahwa besaran analisa window akan memengaruhi hasil INPEFA yang didapatkan. Semakin kecil besaran analisa window yang digunakan akan menghasilkan trend INPEFA yang lebih berfrekuensi tinggi. 


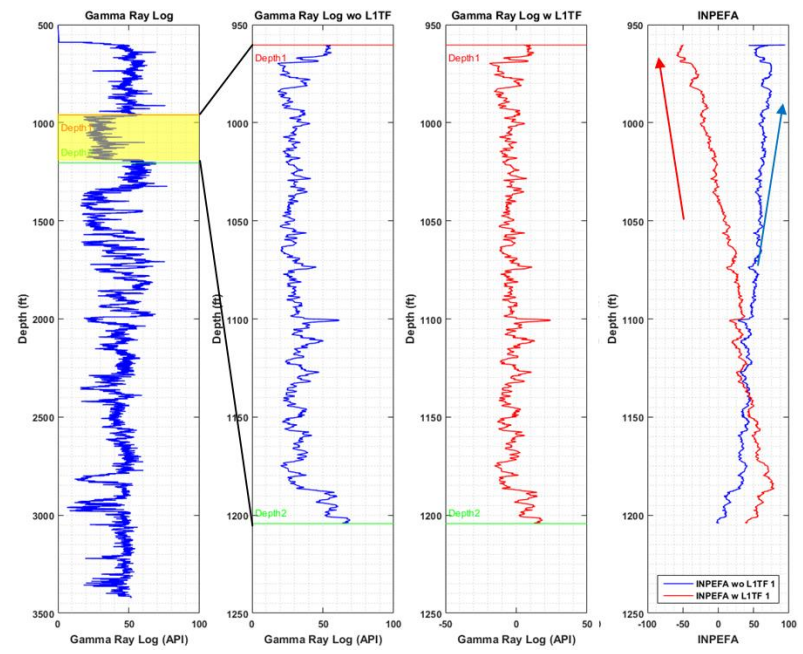

Gambar 4. Hasil eksperimen efek stasionaritas data masukan. Dari kiri ke kanan, kolom pertama merupakan data masukan (dominasi GR log rendah) dengan analisa window ditandai oleh kotak berwarna kuning. Kolom kedua (biru) dan ketiga (merah) merupakan data sebelum dan sesudah dilakukan trend filtering. Hasil INPEFA terletak pada kolom keempat.

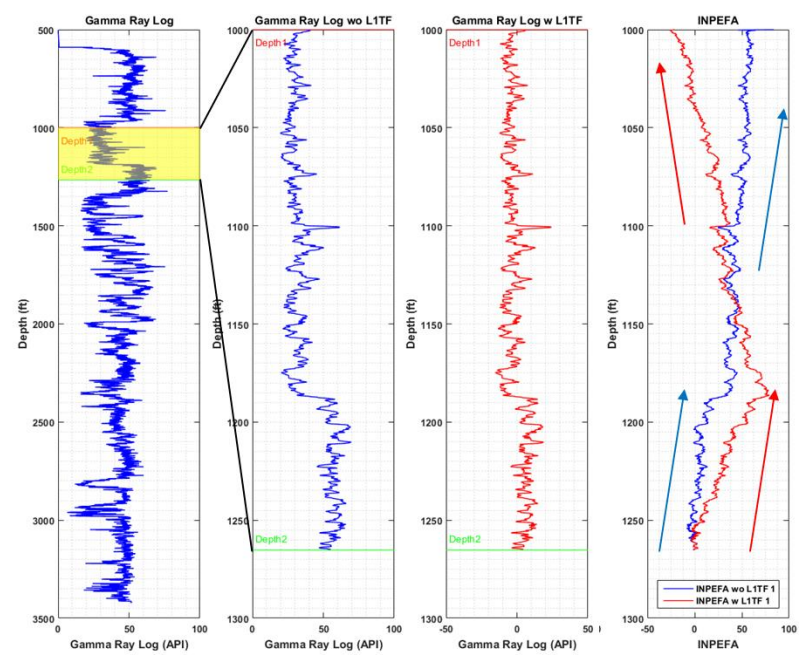

Gambar 5. Hasil eksperimen efek stasionaritas data masukan. Dari kiri ke kanan, kolom pertama merupakan data masukan (dominasi GR log tinggi dan rendah) dengan analisa window ditandai oleh kotak berwarna kuning. Kolom kedua (biru) dan ketiga (merah) merupakan data sebelum dan sesudah dilakukan trend filtering. Hasil INPEFA terletak pada kolom keempat.

\subsection{Validasi Hasil Perhitungan INPEFA}

Identifikasi trend INPEFA memiliki kendala lain dalam pengaplikasiannya yakni dalam hal besar nilai lambda yang dianggap representatif pada semua sumur penelitian. Untuk mengatasi kendala tersebut, dibutuhkan data lain yang bertindak sebagai validator hasil INPEFA dengan kondisi lapangan yang sesungguhnya. Penentuan nilai lambda dapat dilakukan dengan membandingkan tiap-tiap trend INPEFA pada kedua sumur dengan data core atau litologi yang tersedia (gambar 7 kolom paling kanan dan kiri). Dengan membandingkan kekonsistenan trend INPEFA antar kedua
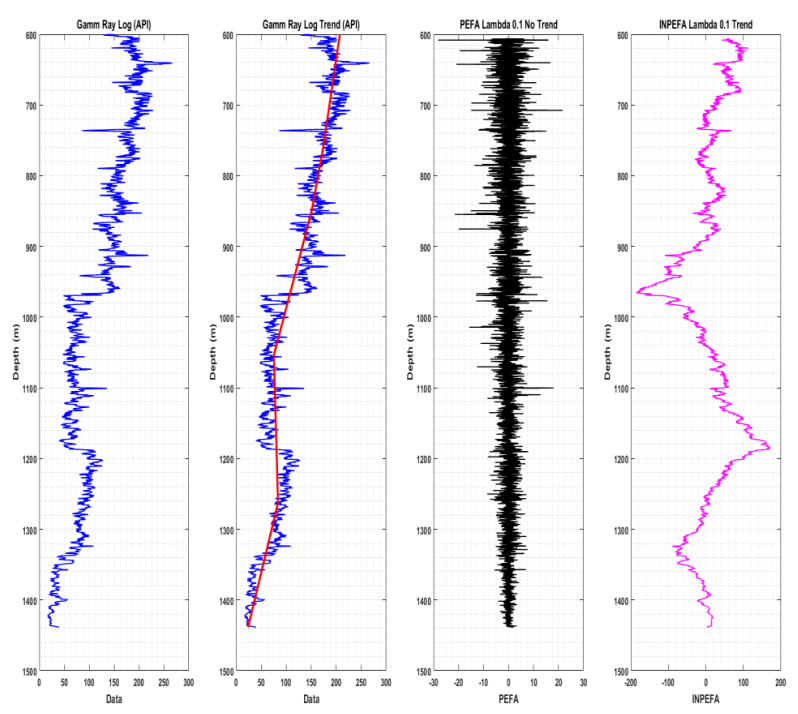

Gambar 6. Hasil eksperimen perubahan besar nilai window pada algoritma filtering yang digunakan. Dari kiri ke kanan, kolom pertama dan kedua merupakan data masukan dan data masukan dengan hasil bacaan trend tiap window data (garis merah). Kolom ketiga dan keempat merupakan hasil perhitungan PEFA dan hasil INPEFA untuk besar window 0.1 .
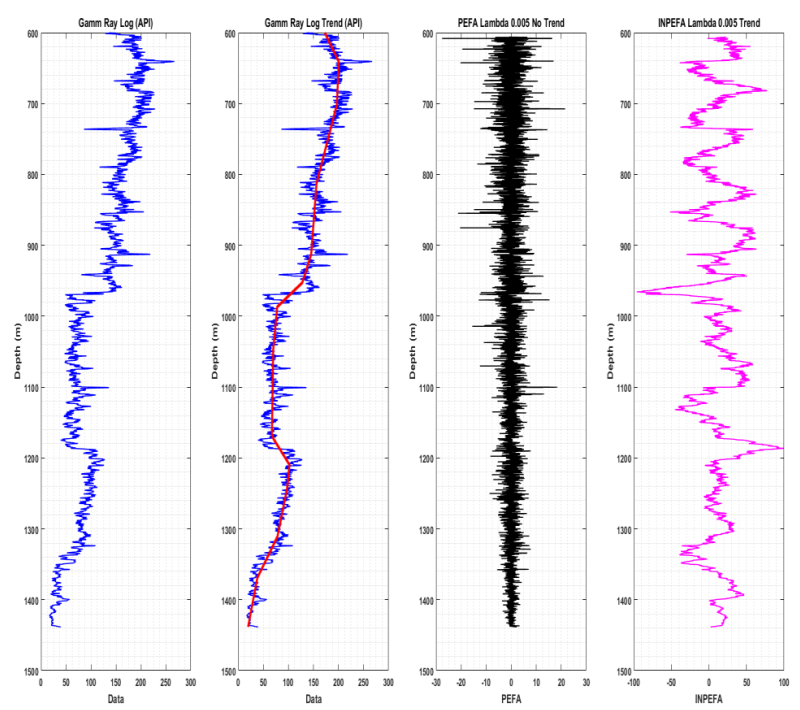

Gambar 7. Hasil eksperimen perubahan besar nilai window pada algoritma filtering yang digunakan. Dari kiri ke kanan, kolom pertama dan kedua merupakan data masukan dan data masukan dengan hasil bacaan trend tiap window data (garis merah). Kolom ketiga dan keempat merupakan hasil perhitungan PEFA dan hasil INPEFA untuk besar window 0.005 .

sumur saat membaca interval dengan litologi yang sama, nilai lambda yang representatif bisa didapatkan.

Hasil trend INPEFA yang didapatkan pada kedua sumur juga mampu divalidasi dengan menggunakan tras seismik. Dengan mengasumsikan setiap titik pada defleksi trend INPEFA berasosiasi dengan perubahan ukuran butir batuan yang dapat diimplikasikan sebagai perubahan impedansi, hasil trend INPEFA mampu divalidasi lebih lanjut menggunakan data seismik yang tersedia. Pada Gambar 


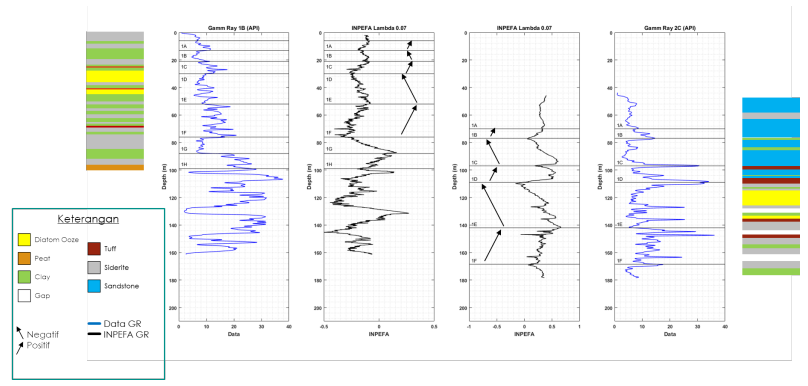

Gambar 8. Hasil validasi perhitungan INPEFA dengan data litologi (kolom paling kanan dan kiri) yang tersedia. Pola-pola INPEFA (panah hitam) digunakan sebagai acuan penentuan batas unit-unit sedimen (garis horizontal).

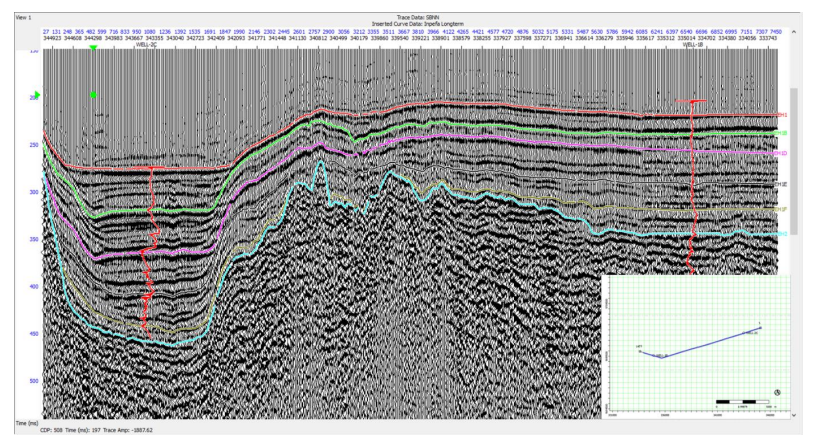

Gambar 9. Hasil validasi perhitungan INPEFA dengan data seismik yang tersedia pada lapangan penelitian. Tras seismik dibangun dengan menggabungkan dua line seismik yang melewati kedua sumur penelitian seperti tertera pada peta bagian pojok kanan bawah.

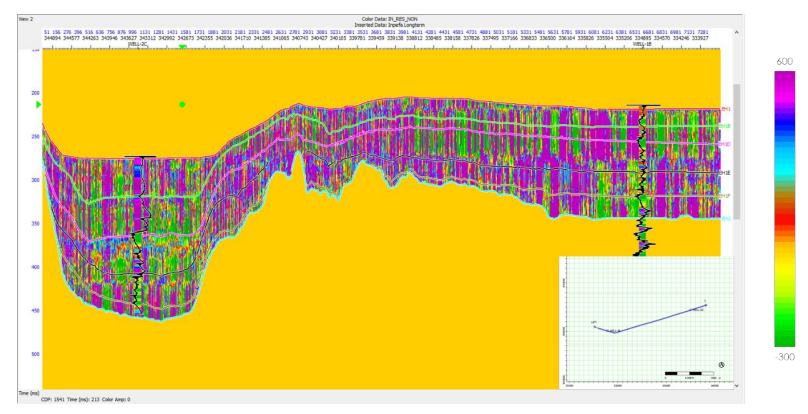

Gambar 10. Penampang hasil proses multiatribut seismik. Garis-garis berwarna hitam menunjukkan INPEFA log pada kedua sumur penelitian.

8 dapat dianalisa pada setiap titik perubahan trend INPEFA berasosiasi dengan strong reflection pada tras seismik.

\section{KESIMPULAN}

Pada perhitungan koefisien Burg, variasi nilai orde atau lag yang digunakan tidak memengaruhi trend yang dihasilkan. Semakin besar nilai lag akan menunjukan amplitudo trend yang semakin lemah, namun tidak memengaruhi jumlah trend yang dihasilkan. Proses trend removal dalam pengondisian stasionaritas data masukan yang digunakan. Proses

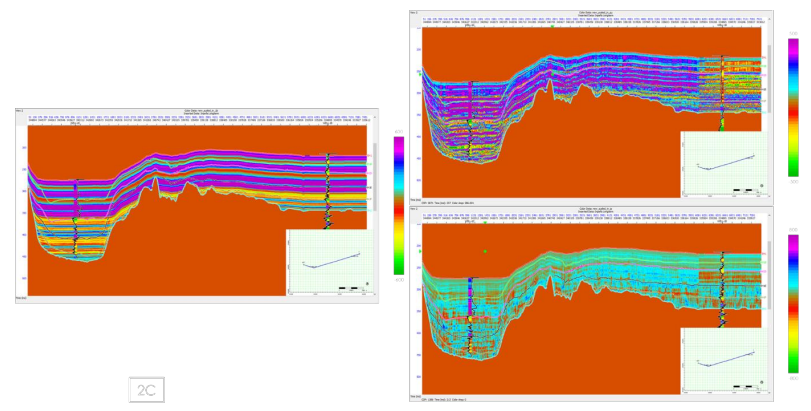

Gambar 11. Penampang hasil transformasi FWO dengan berbagai data masukan; impedansi akustik (kiri), instantaneous phase (kanan atas), dan quadrature (kanan bawah).
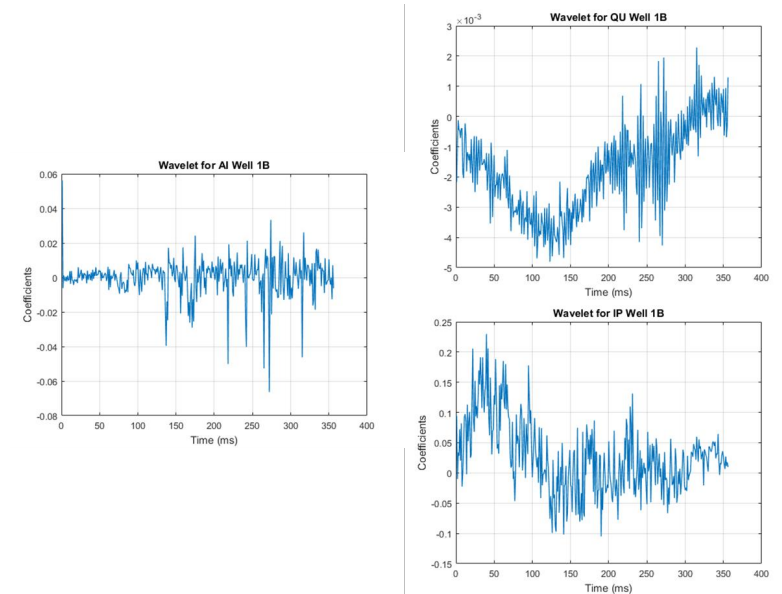

Gambar 12. Koefisien FWO untuk berbagai data masukan; impedansi akustik (kiri), instantaneous phase (kanan atas), dan quadrature (kanan bawah).

ini penting untuk dilakukan karena sifat stasioner data akan memengaruhi hasil INPEFA yang didapatkan. Secara spesifik, data yang tidak stasioner akan menghasilkan ambiguitas pada hasil INPEFA. Analisa variasi nilai lambda menunjukan bahwa, variasi nilai lambda akan memengaruhi trend INPEFA yang dihasilkan. Semakin kecil nilai lambda akan menghasilkan trend INPEFA yang lebih detil (high frequency). Hal ini dapat diartikan sebagai siklus yang lebih bersifat short-term, sehingga dapat disimpulkan bahwa perubahan nilai lambda juga dapat berguna dalam analisa berbagai siklus yang mungkin terjadi. Hasil korelasi menggunakan trend INPEFA pada penelitian ini mampu divalidasi dan memetakan unit-unit sedimen dengan nilai GR log yang berbeda. Selain data litologi, hasil perhitungan juga divalidasi oleh tras seismik yang melintasi kedua sumur. Perubahan trend INPEFA dapat diinterpretasikan sebagai perubahan impedansi litologi dan mampu ditunjukkan oleh adanya refleksi pada tras seismik.

\section{DAFTAR PUSTAKA}

Nio S.D., Brouwer J.H., de Jong M.G.G. dan Bhm A.R. (2005). spectral trend attribute analysis: applications in 
the stratigraphic analysis of wireline logs, First Break, $23,71-75$.

Prabowo, K., Nicholas, J., Winardhi, S. (2011). Enhancing pore pressure analysis through integrated prediction error filter analysis, SEG Annual Meeting Perth 2011.

Soua, M. (2012). Application of Facies Associations, Integrated Prediction Error Filter Analysis, and Chemostratigraphy to the Organic-Rich and Siliceous Cenomanian-Turonian Sequence, Bargou Area, Tunisia: Integrated Sequence Stratigraphic Analysis, Journal of Geological Research, 22, 1-15.

Russell, J. M., Bijaksana, S., Vogel, H., Melles, M., Kallmeyer, J., Ariztegui, D., Crowe, S., Jannatul Fajar, S., Hafidz, Abd., Haffner, D., Hasberg, A., Ivory, S., Kelly, C., King, J., Kirana, Kartika H., Morlock, M., Noren, A., OGrady, R., Ordoez, L., Stevenson, J., von Rintelen, T., Vuillemin, A., Watkinson, I., Wattrus, N., Wicaksono, S., Wonik, T., Bauer, K., Deino, A., Friese, A., Henny, C., Imran, Marwoto, R., Ngkoimani, L.O., Nomosatryo, S., Safiuddin, L.O., Simister, R., Tamuntuan, G. (2016). The Towuti Drilling Project: Paleoenvironments, biological evolution, and geomicrobiology of a tropical Pacific lake. Scientific Drilling, 21, $29-40$.

Huang, J. (2014). Study of autoregressive (ar) spectrum estimation algorithm for vibration signals of industrial stream turbines, International Journal of Control and Automation, 7, 349-362.

Teja, R. V., Rakesh, U., dan Rao S. K. (2017). Spectral analysis of seismic signals using burg algorithm, International Journal of Pure and Applied Mathematics, 114, 163-171.

Vaidyanathan, P. P. (2008). The theory of linier prediction, California Institute of Technology, 198pp. 